\title{
Социальная активность молодежи: системно-диахронический подход
}

\section{Раиль М. Шамионов}

Саратовский национальный исследовательский государственный университет имени Н. Г. Чернышевского, г. Саратов, Российская Федерация

E-mail: shamionov@mail.ru

\section{Аннотация}

Введение. Актуальность исслеАования социальной активности связана с необхоАимостью изучения ее психологических механизмов, благодаря которым происходят формирование поведенческих стратегий, реализация поступков и послеАовательного поведения в социальной среде. Цель исследования - в применении методологических положений системно-Аиахронического поАХоАа к анализу социальной активности, ее механизмов и Аетерминант. Применение оригинального системно-Аиахронического поАХоАа позволит раскрыть ее сложную внутреннюю организацию, разработать среАства риск-менеАжмента активности мололежи. Теоретическое обоснование. Современные исследования социальной активности сосредоточены на анализе ее мотивации, солержания, оракторов, уровней, социальных рисков. Социальная активность рассматривается с точки зрения социальных и личностных эфффектов как способ социального участия и самореализации человека. Отмечается особый интерес исследователей к протестной и гражАанской активности молодежи. На основе анализа различных источников САелан вывоА о неАостаточной разработанности в социальной психологии проблемы социальной активности, трудностях операционализации ореноменов социальной активности мичности и группы, о необходимости обобщения разрозненных Аанных о ее основаниях, побудителях, механизмах и общественных эфрфректах. Результаты и их обсужление. ПреАложено определение социальной активности как фрундаментального эфффекта социализации личности, заключающегося в способности инициативного возАействия социальных субъектов на окружающую социальную среду, предполагающего не только участие в общественной жизни, но, прежле всего, реализацию инициативно-творческого отношения к сорерам своей социальной жизнеАеятельности, а также самой себе как субъекту социального бытия. ОбсужАены особенности системно-диахронического подхода к анализу социальной активности. Система социальной активности рассмотрена как система со встроенным метасистемным уровнем социальной Аействительности. Отмечена нелинейная Аинамика социальной активности личности, обусловленная Аиахронией ее внутренних и внешних инстанций. Рассмотрены ее побудительные 


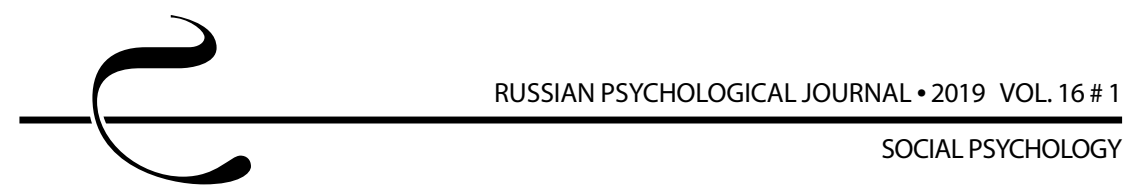

и содержательные механизмы и факторы, дифореренцированные в зависимости от этапа социализации мичности, Аостижения социальной зрелости. Раскрыты важнейшие характеристики - мичностные регуляторы социальной активности инициатива, самостоятельность, ответственность, социальный интеАлект.

\title{
КАючевые слова
}

^ичность, субъект, социальная активность, система, метасистема, Аиахрония, социализация, механизмы, фракторы, мололежь

\section{Основные положения}

- на основе теоретического анализа выявлены существенные признаки социальной активности Аичности (инициативность, вКАюченность, социально преобразующая направленность, самостоятельность и Ар.);

- установлена связь уровней социальной активности с социализацией ^ичности; - раскрыты особенности системно-диахронического подхола к анализу социальной активности Аичности (исслеАование Аинамики внутренних характеристик и фракторов, их определяющих, качественных изменений в системе и ее эфоректов).

\section{Для цитирования}

Шамионов Р. М. Социальная активность молодежи: системно-диахронический подход // Российский психологический журнал. 2019. Т. 16, № 1. С. 166-188. DOI: 10.21702/rpj.2019.1.8

Материалы статьи получены 14.05.2018

UDC 316.6:159.923

DOI: $\underline{10.21702 / \text { rpj.2019.1.8 }}$

\section{Social Activity of Youth:} A Systematic Diachronic Approach

\section{Rail M. Shamionov}

National Research Saratov State University named after N. G. Chernyshevsky, Saratov, Russian Federation

E-mail: shamionov@mail.ru

\begin{abstract}
Introduction. This paper concentrates on studying psychological mechanisms of social activity, which determine individuals' behavioral strategies, actions, and sequential behavior in the social environment. By applying a systematic diachronic approach, this study was undertaken to analyze social activity, its mechanisms, and determinants. The original systematic diachronic approach is capable of revealing the complex
\end{abstract}


internal organization of social activity and may help develop means for managing risks among youth.

Theoretical Basis. Current research on social activity is focused on its motivation, content, factors, levels, and social risks. Social activity is considered in terms of social and personal effects as a way of social participation and self-realization. Young people's protest and civil activities are of particular interest to researchers. A review of literature revealed that little emphasis has been placed on the issues of social activity and difficulties in operationalization of the phenomena of social activity among individuals and groups. Thus, disparate data on its foundations, driving forces, mechanisms, and public effects should be brought together.

Results and Discussion. Social activity is a fundamental effect of the socialization of individuals, which determines social subjects' initiative impact on the social environment, their participation in social life, and initiative and creative relation to all social spheres, as well as self-relation. The system of social activity is considered as a system containing a meta-system level of social reality. This study (a) discusses characteristics of the systematic diachronic approach to the analysis of social activity, (b) establishes a nonlinear dynamics of social activity of individuals which is caused by diachrony of its internal and external instances, (c) considers its incentive and structural mechanisms and factors, which are differentiated by the stage of individuals' socialization and their social maturity, and (d) reveals the most important personal characteristics that regulate social activity including initiative, independence, responsibility, and social intelligence.

\section{Keywords}

personality, subject, social activity, system, metasystem, diachrony, socialization, mechanisms, factors, youth

\section{Highlights}

- The review of the scientific literature revealed fundamental characteristics of individuals' social activity such as initiative, engagement, socio-transforming orientation, and independence.

- The relationship between socialization and the levels of social activity was discussed.

- The study describes the features of the systematic diachronic approach to the analysis of individuals' social activity including the dynamics of internal characteristics and their factors, qualitative changes in the system, and its effects.

\section{For citation}

Shamionov R. M. Social Activity of Youth: A Systematic Diachronic Approach. Rossiiskii psikhologicheskii zhurnal - Russian Psychological Journal, 2019, V. 16, no. 1, pp. 166-188 (in Russian). DOI: 10.21702/rpj.2019.1.8 


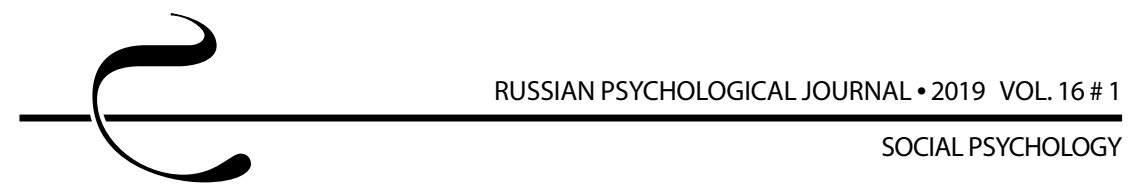

\section{Введение}

Социальные процессы, происходящие в современном мире, в значительной степени отражаются на характере социальной активности молодежи и в немалой степени обусловлены ею. Они побуждают социальную активность молодежи в различных ее ипостасях, расширяют возможности ее приложения и обусловливают инициирование новых ее видов. С другой стороны, потенциал социальной активности молодежи необходим для инновационных общественных и экономических изменений. Между тем, в социальной психологии, несмотря на то, что анализ социальной активности личности ведется со времен разработки концепции героя и толпы Н. К. Михайловского [1] и социального поведения У. Мак-Даугалла [2], имеется недостаток научных знаний о генезе, побудительных ее механизмах и детерминантах. Таким образом, разработка проблемы социальной активности характеризуется социальной и научно-практической значимостью.

\section{Теоретическое обоснование}

Важнейшим признаком социальной активности является включенность личности и групп в социальное взаимодействие $[3,4,5,6]$ и социально-одобряемую деятельность [6, 7].

Исследования социальной активности молодежи в последние десятилетия сосредоточены вокруг проблемы ее определения и операционализации [4], установления уровней [7, 8], форм [4], рисков [4, 5], адаптации в социальном пространстве [9], мотивационных механизмов [9, 10], интеграции исследований [11]. Множество исследований охватывают конкретные формы или проявления социальной активности, анализируя их частоту, востребованность и значимость для общества. Так, изучаются: социальная активность молодежных объединений [12]; социальная активность в связи с гражданскими инициативами $[13,14]$; уровни социальной активности в социально-преобразующей деятельности [8], как элемент социального самоопределения [15], в контексте гражданской идентичности [16]; альтруистическая социальная активность [17]; трансформация политических обсуждений в политические действия и политическую активность $[18,19]$; влияние добровольчества молодежи в политической агитации на их политическую осведомленность [20]; гражданская активность во взаимосвязи с характеристиками неравенства [21].

Поскольку в значительной степени отмечаются рост политической активности молодежи и ее омоложение (если в 2012 г. протестная активность рассматривалась исследователями как наименее значимая для молодежи [22], то в последнее время наблюдается явный рост политической активности молодежи вообще и протестной, в частности [23]), ее исследования заметно 
активизировались. Так, подобная активность рассматривается сквозь призму инновационного развития общества как необходимая его составляющая [24], механизмов продвижения политической активности молодежи [25], влияния СМИ на общественно-политическую деятельность молодежи [26], влияния молодежных общественных объединений на будущую политическую деятельность (на основе лонгитюдного исследования) [27].

Ряд работ посвящен анализу социально-психологических детерминант социальной активности. В частности, проведены исследования отношения к социальной активности во взаимосвязи с субъектными характеристиками, адаптации личности [9] в зависимости от вида реализуемой активности, через организованную социальную активность [28], социально-демографические детерминанты социальной активности [20], факторов социальной апатии и отказа от традиционных форм политической активности [29], социального доверия молодежи как фактора социальной активности [30].

Особой сферой социальной активности в последние десятилетия становится виртуальная среда. М. Д. Завгородний, анализируя социальную активность молодежи в сети Интернет, приходит к выводу о наиболее высокой распространенности социально-преобразующей деятельности индивидов в рамках одной или нескольких сфер, в первую очередь, познавательно-творческой, общественной и политической [31]. Между тем, интерес исследователей к данным формам активности в последние годы заметно усилился, что связано с ростом сетевого взаимодействия молодежи [32, 33, 34, 35, 36]. Особый интерес связан с политической активностью в интернет-сообществах и влиянием на политическую активность молодежи в них [37, 38], в том числе с прямым влиянием через сетевые сообщества на реализуемое протестное поведение [39], а также влиянием онлайн-активности, основанной на дружбе и интересах, на политику участия в Интернете и на автономные формы политических действий [25]. Установлено также, что использование социальных сетей молодежью может способствовать более активному политическому и гражданскому участию [40].

В ряде исследований отмечается значимость анализа самоопределения [41], преобразовательной активности [42], экзистенциального опыта [43] в различных ипостасях социальной активности молодежи.

Наконец, предложены социальные технологии управления социальной активностью [28, 44], связанные с раскрытием социального потенциала молодежи и его активизацией, поддержкой социальных инициатив молодых людей.

Необходимо отметить и то, что проблема социальной активности молодежи в настоящее время широко обсуждается на научных форумах, представлена во множестве публикаций. По нашим подсчетам, по базе РИНЦ таковых только за последние два года насчитывается более тысячи. 


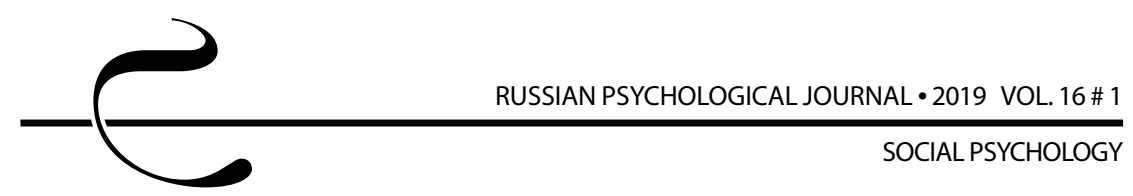

В результате анализа исследований социальной активности молодежи, проведенных в России и за рубежом, мы пришли к выводу об усиленном интересе к вопросу о приложении социальной активности к гражданско-правовой сфере и связанной с ней сфере политической активности. Это касается и организованной социальной активности, и неорганизованной в условиях выхода социальной активности в виртуальную среду. Тем не менее, как в отечественной, так и в зарубежной психологии важное место отводится альтруистической активности личности и групп; значительно меньше уделяется внимание досуговой активности, социально-экономической, образовательно-развивающей и духовной активности.

Социальная активность понимается как частный случай инициативного воздействия социальных субъектов на окружающую социальную среду. Социальная активность личности и групп предполагает не только участие в общественной жизни, но, прежде всего, реализацию инициативно-творческого отношения к сферам своей социальной жизнедеятельности, а также самой себе как субъекту социального бытия.

Социальная активность личности является закономерным эффектом социализации. Это активность, направленная на изменение и преобразование социальных объектов, в результате которой происходит изменение самой личности и всей социальной ситуации. Она порождается в результате обретения человеком тех свойств субъекта и личности, которые предопределены его включением в деятельность социальных групп, в социальную активность Других, где происходит усвоение норм, ценностей и установок, очерчивающих границы возможной активности, ее направления. В этом смысле источником социальной активности личности являются совокупный социальный опыт предшествующих поколений и социальные потребности индивида. Личностное отношение к социальной активности предполагает установление ее соответствия актуальным потребностям индивида, ценностно-нормативным и смысловым представлениям личности, наконец, устойчивым социально-психологическим и психодинамическим свойствам личности. Вполне очевидно то, что от субъектной позиции личности зависит степень инициативы в социальной активности, а ее направления - от представлений личности о границах собственной активности, отношения к ней.

Несмотря на значительный интерес к проблеме социальной активности, в науке имеется существенный недостаток теоретических концепций социальной активности, отсутствие теоретических обобщений, операционализации феноменов социальной активности личности и группы, комплексных исследований ее детерминант. На наш взгляд, одним из наиболее продуктивных для анализа социальной активности личности может служить разработанный нами ранее и примененный для исследования социализации 
личности системно-диахронический подход [45]. Цель данного исследования заключается в обсуждении особенностей системно-диахронического подхода к изучению социальной активности личности, ее механизмов и детерминант.

\section{Результаты и их обсуждение}

Системно-диахронический подход к социальной активности опирается на положения комплексного, системного, метасистемного, субъектно-бытийного подходов и методологический принцип диахронии $[46,47,48,49$, $50,51,52,53,54,55,56]$.

Использование системно-диахронического подхода к социальной активности личности предполагает раскрытие системно-структурных особенностей данного объекта и его динамических характеристик, включая множественные изменения его составляющих. Поэтому одним из центральных вопросов здесь становится вопрос о внутренних движениях, нарушающих баланс системы и служащих основой активности личности. Социально-психологический анализ этих изменений, как показано нами ранее [56], позволяет определить наиболее значимые, с точки зрения социальной активности, движения системы - не просто анализ определенных социально-психологических характеристик, а изучение их конфигурации, соотношений, выдвижения одних (роста, стабилизации) и регрессивных изменений (спада) других.

В соответствии с системно-диахроническим подходом социальная активность личности представляет собой систему со сменными основаниями. Смена оснований связана как с этапом социализации и соответствующими ему достижениями в усвоении социальных норм, ценностей, установок и моделей поведения, так и достижением личностной зрелости индивида. Поэтому в различных условиях социального бытия и на разных этапах социализации возможны принципиальные различия социальной активности по ее направленности и по глубине и критериям субъектной позиции - ответственности-самостоятельности. Кроме того, в соответствии с ним же возможны переходы социальной активности из одной сферы направленности в другую, из одного сообщества в другое, сферы виртуальной реальности в физическую, и наоборот.

Необходимо отметить, что в соответствии с принципом диахронии динамика событий или явлений рассматриваются сквозь призму последовательности, скорости изменений, темпоритмических характеристик [54, 56, $57,58]$. Это не только разно-временность, но и со-временность изменений разных характеристик личности, группы, социума. Иначе говоря, явления рассматриваются сквозь призму происходящих в них изменений во времени, которые могут приобретать разнонаправленность (диахрония) или однонаправленность (синхрония). Для предмета нашего обсуждения этот 


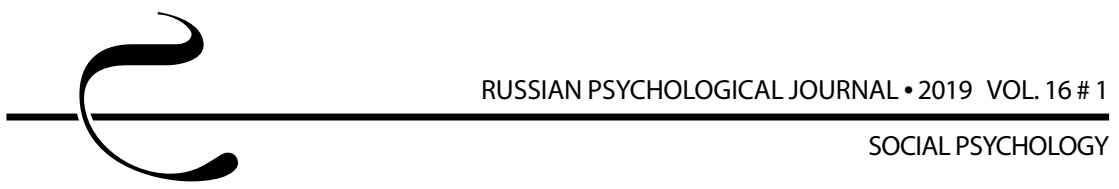

принцип является ведущим, поскольку современные социальные процессы характеризуются неопределенностью, частотой смены прогресса и регресса, обнаруживающейся временной дифференциацией изменений в различных сферах, что неминуемо отражается на личности и сообществах.

Принцип диахронии в психологических исследованиях рассматривается в контексте развития [54, 59], социализации [45], адаптации [57] личности. Применительно к социальной активности реализация этого принципа связана с анализом, во-первых, временного аспекта социальной активности, включая ее хронологию, согласованность/несогласованность внешним и внутренним инстанциям личности, что отражается на удовлетворенности/неудовлетворенности собой, своей активностью и ситуацией, и, во-вторых, временных согласований/рассогласований личности и среды реализации активности. Очевидно, «попадание» в различные темпоритмические фазы создает очаг напряженности, который является движущей силой активности. Поэтому неслучайно, например, неудовлетворенность собой выступает в качестве побудительного механизма усвоения новых норм и моделей социального поведения, либо выполнения действий, направленных на достижения определенного социального статуса, в целом, социальной самореализации личности и т.п. Отметим также и то, что в соответствии с системно-диахроническим подходом социальная активность личности рассматривается как производная от личностных эффектов социализации и социального взаимодействия личности. Поэтому социальная активность должна рассматриваться как система со встроенным метасистемным уровнем социальной действительности. В соответствии с метасистемным подходом [49], социальная действительность для личности конвергируется на двух основных уровнях - социального микро- и макроокружения, поскольку социум «...воспроизводит себя в содержании структуры личности; он "встраивается" в ее содержание и структурно-функциональную организацию и даже во многом образует ее» [49, с. 289]. Иначе говоря, одной из важнейших задач в исследовании социальной активности личности становится задача определения этого «метасистемного согласования», выявления базовых условий социальной активности личности на уровне «заложенных» социальных форм, имеющих часто скрытый характер, а также актуальных на уровне существующих связей с конкретными социальными группами.

Нелинейность социальных изменений обладает дестабилизирующим личность и группу началом, порой разрушая эффективные и привычные механизмы адаптации. Нелинейность социальных изменений, диахронность социальных явлений, касаются они наиболее значимых для молодежи сфер или нет, вводит в систему взаимодействий «личность - среда», «группа - социальная среда» опосредующую переменную - адаптационную готовность. Это связано с тем, что дестабилизация в системе вынуждает социального субъекта 
предпринять меры для восстановления динамического равновесия. Поэтому известная адаптационная готовность служит своего рода амортизатором, облегчающим адаптацию, и если не устраняющим, то хотя бы облегчающим влияние резких внешних изменений или дестабилизации ситуации (как, например, происходит в условиях различных политических, экономических или социальных кризисов).

Необходимо также отметить и то, что реализация социальной активности может характеризовать определенные регрессивные изменения личности. В частности, приобретение определенной направленностью личности качеств доминирующей может привести к стагнации или регрессу других. Такая диахрония является внутренней и побуждает личность к уравновешиванию ее инстанций, что отражается на ее активности. Таким образом, принцип диахронии может быть применен как к анализу внутренних (инстанционных) отношений, так и отношений в системе «личность - среда», т. е. распространяться на встроенный метасистемный уровень социальной реальности. Именно последнее позволяет объяснить стабильность/нестабильность социальной активности личности, включение в различные сообщества, реализующие ее в определенных условиях и в отдельные эпохи (например, на уровне так называемых субкультур), изменения качества социальной активности личности в результате ее собственного развития и социализации, наконец, отказ от социальной активности в условиях масштабных регрессивных изменений личности, либо социума, наконец, соотношений ее детерминант.

Анализ психологической картины социальной активности личности предполагает выяснение также ряда ключевых вопросов: источников активности, ее побудительных механизмов, видов или форм активности, уровней активности, области активности, критериев оценки, наконец, детерминант.

Социальная активность личности возникает в результате взаимодействия личности с социальной средой. Поэтому целесообразно говорить о разных уровнях активности на разных этапах социализации личности. В соответствии с результатами наших исследований в процессе социализации расширяется и область приложения социальной активности личности, и пространство активности, а также ее последствия для личности и социальной среды. Поэтому необходимо рассматривать не только уровни по широте/узости охвата (приложений) активности (микро-, мезо-, макроуровни), но и по включению в социум - индивидуальную социальную активность, групповую и массовую. Эти уровни можно рассматривать как с точки зрения ее социальных эффектов, так и продуктивности для личности и групп. Иерархизация уровней социальной активности является важным достижением социализации, поскольку позволяет соотносить их по степени значимости, приемлемости. Кроме того, возникает возможность практически одновременной фиксации нескольких 
видов социальной активности и самореализации в них, благодаря расширению бытийных пространств (по 3. И. Рябикиной) личности.

Важнейшими социально-психологическими характеристиками социальной активности являются инициатива [6], общая самостоятельность [60], ответственность $[6,61]$, социальное мышление и интеллект $[6,62]$, доверие [6]. Инициативность является ведущей характеристикой социальной активности. По мысли К. А. Абульхановой, она предполагает «опережающую внешние требования или встречную по отношению к ним свободную активность субъекта» [6, с. 57]. Ее появление связано с условиями социализации личности, подкреплением на разных уровнях - микро- и макроуровнем взаимодействия с Другими.

Необходимо отметить и то, что соотношение социальной активности и ответственности за ее последствия является критерием ее (активности) зрелости и, очевидно, критерием личностной зрелости. Данный вопрос не является праздным в силу распространенной рассогласованности в этой системе, заключающейся в том, что отказ от ответственности либо ее неприятие в социальной активности часто приводит к ситуации ее противопоставления социальным нормам, либо даже правовым нормам. В соответствии с системно-диахроническим подходом такое рассогласование относится к числу тех, которые разрушают систему взаимодействия личности и общества, создавая высокий уровень риска для существования той или иной инстанции вообще. Соотношение самостоятельности и социальной активности обусловлено субъектной позицией личности: в случае опоры на собственное мнение, суждения, качества, либо на чужие, социальная активность характеризуется как автономная или зависимая, т. е. реализуемая в канве активности других. Очевидно, и ответственность в этом случае чаще возлагается на внешние обстоятельства или других лиц. Иначе говоря, социальная активность может быть как инициативной, автономно управляемой, так и зависимой, реализующейся в русле активности других людей, организуемой и управляемой другими.

Способность понимать других людей, взаимоотношения с ними, в целом, социальные ситуации, связаны с такой характеристикой, как социальный интеллект. Эффективность форм взаимодействия личности с социальными субъектами связана именно с социальным мышлением. Однако, как было показано нами ранее, оно в значительной мере подвержено влиянию со стороны личностных характеристик индивида, которые могут блокировать его, порождая неконгруэнтность поведения [4]. По утверждению Д. В. Ушакова, социальный интеллект позволяет, оценив ситуацию и участвующих в ней людей, более адекватно выстраивать стратегию поведения [62]. Очевидно, социальный интеллект позволяет более критично относиться к различным формам социальной активности и понимать мотивацию участвующих в ней людей. 
Таким образом, инициативность, самостоятельность, ответственность, доверие и социальный интеллект являются не просто социально-психологическими характеристиками, но личностными регуляторными инстанциями социальной активности, обусловливая степень субъектной регуляции активности - ее интенсивность, мотивированность, рефлексивность, контролируемость, понимание - важнейших ее системных характеристик.

Механизмы социальной активности личности и группы, на наш взгляд, необходимо рассматривать сквозь призму не операциональной их стороны, а побудительной. Одним из главных их признаков является преобразование интереса, ценности, цели в действие, деятельность. Однако в случае социальной активности в эту связь вклинивается социальный процесс, который не просто порождает или добавляет новые потребности, ценности и смыслы, но и придает особую динамику в реализацию социальной активности. Побудительным механизмом социальной активности являются диахронические изменения в системе «личность - социальная среда». На ранних этапах социализации действие этого механизма связано с противоречием между зарождающимися социальными потребностями, либо их сменой на потребности более высокого уровня и «притормаживающего» ее влияния социальной среды. На более поздних этапах данный механизм срабатывает в виде рассогласованности когнитивного развития личности, стремления к обособлению от прежних условий реализации социальной активности для их обновления в виду расширения возможностей для этого и, соответственно, проб себя в различных видах активности и снижения уровня связи с первичной группой. В результате сепарирования с прежними условиями реализации активности (в том числе с первичной группой) происходит относительно безбарьерное включение в различные формы социальной активности, в том числе и рискованные.

Необходимо также отметить и то, что если на ранних этапах социализации социальная активность обусловлена психофизиологическими и зарождающимися социально-психологическими характеристиками личности, то на более поздних этапах - социально-психологическими и этико-психологическими. Это связано с тем, что на каждом этапе социализации социальная активность обусловлена разными характеристиками личности и социальной среды - не только собственными диспозиционными образованиями, репрезентированными социальными установками, представлениями и ценностями, но и меняющимся отношением к человеку извне на основе его социально-возрастного статуса личности, обретения им атрибутов гражданственности, а также принадлежности к различным групповым образованиям и других характеристик.

В целом, как было показано нами ранее [4], социальная активность определяется как внешними (общая социальная ситуация, возможности реализации активности, плюрализм и толерантность к инакомыслию, межгрупповая 


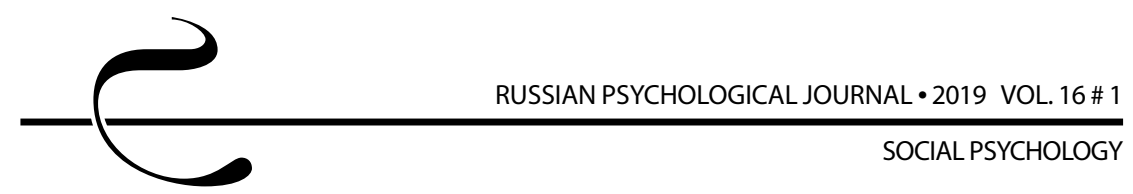

толерантность, принятие «иных», терпимое отношение к социальным аутсайдерам в обществе и т. п.), так и внутренними (жизненная позиция, социальные представления личности, отношения, диспозиции, социальный интерес, свойства, феномены самоопределения и пр.) факторами.

\section{Заключение}

Таким образом, анализ социальной активности личности и группы с позиций системно-диахронического подхода предполагает выявление разнонаправленной и синхронной динамики отдельных характеристик в системах «личность - социальная среда», «группа - социальная среда», а также качественных изменений в этих системах в виде сменности оснований, условий, детерминант (внутренних и внешних), достигаемых эффектов социальной активности, обратной связи и т. д. Поэтому оценка социальной активности личности и группы должна предполагать, по крайней мере, два рода эффектов: постепенно накапливаемые, меняющиеся линейно вне зависимости от смены вида активности, знаменующие эволюционный опыт социальной активности, который становится индивидуальным достижением в социализации личности, и характеризующиеся сменой в зависимости от конкретного вида социальной активности, где прежняя активность становится основанием для новой.

Исследования динамических характеристик, механизмов и детерминант социальной активности личности позволят раскрыть психологическую картину этого явления, объяснить ее происхождение и функционирование. Важнейшим обстоятельством является то, что социальная активность обусловлена не одним единственным механизмом: имеется ряд психологических механизмов, среди которых, очевидно, наиболее важным является диахроническое рассогласование в системе «личность - среда (микро- и макроокружение)» на различных уровнях взаимодействия. Исследования отечественных и зарубежных авторов убеждают в том, что социальная активность личности связана не только с собственно личностной регуляцией, но множественной внешне социальной, где реализуются различные взаимодействия личности (включая деперсонализированные события, информацию, ситуацию). Поэтому необходимы не просто сравнительные исследования характеристик личности, реализующей ту или иную форму активности, но исследования, позволяющие выяснить причинно-следственные связи, приводящие к пониманию как причин активности, так и ее последствий для личности, ее окружения, общества в целом. Такое знание позволит решить задачу реализации программ риск-менеджмента социальной активности молодежи, а также оказать существенную помощь в социализации личности, в достижении ее фундаментальных эффектов, отражающихся не только на индивидуальной судьбе человека, но и судьбе всего общества. 


\section{Благодарности}

Работа выполнена в рамках проекта РНФ № 18-18-00298.

\section{Acknowledgments}

This work was supported by a grant from the Russian Science Foundation (18-18-00298).

\section{Литература}

1. Михайловский Н. К. Герои и толпа // Избр. труды по социологии: В 2 т. Т. 2. СПб.: Алетейя, 1998. 406 с.

2. Мак-Даугал У. Основные проблемы социальной психологии. М.: Космос, 2016. 282 c.

3. Григорьева М. В. Синергетичность школьных интеракций // Известия Саратовского университета. Новая серия. Серия: Философия. Психология. Педагогика. 2009. Т. 9, № 2. С. 68-73.

4. Шамионов Р. М. Психологические характеристики социальной активности личности // Мир психологии. 2012. № 3. С. 145-154.

5. Шамионов Р. М., Григорьева М. В. Психология социальной активности молодежи: проблемы и риски. Саратов: Изд-во Сарат. ун-та, 2012. 384 с.

6. Абульханова-Славская К. А. Психология и сознание личности (проблемы методологии, теории и исследования реальной личности): избр. психол. тр. М.: Изд-во Московского психолого-социального института; Воронеж: НПО «МОДЭК», 1999. 224 с.

7. Соколова Е. С. Структурный подход к пониманию мотивации социальной активности молодежи // Знание. Понимание. Умение. 2008. № 2. URL: http://www.zpu-journal.ru/e-zpu/2008/2/Sokolova/ (дата обращения: 08.04.2018)

8. Еремина Л. И. Соотношение креативности и социальной активности студентов в социально-преобразующей деятельности // Известия Саратовского университета. Новая серия. Акмеология образования. Психология развития. 2015. Т. 4, № 2. С. 155-159.

9. Григорьев А. В. Личностные качества и характеристики отношений к активности как предикторы социально-психологической адаптации личности в зависимости от направлений реализуемой активности // Современные проблемы науки и образования. 2014. № 5. С. 630. URL: https://www.science-education.ru/ru/article/view?id=14546 (дата обращения: 08.04.2018).

10. Заболоцкий В. А. О механизмах мотивации влияющих на социальную активность студентов // Казанская наука. 2015. № 6. С. 202-204.

11. Балабанова E. С. Развитие представлений о социальной активности молодежи в отечественных социально-психологических исследова- 


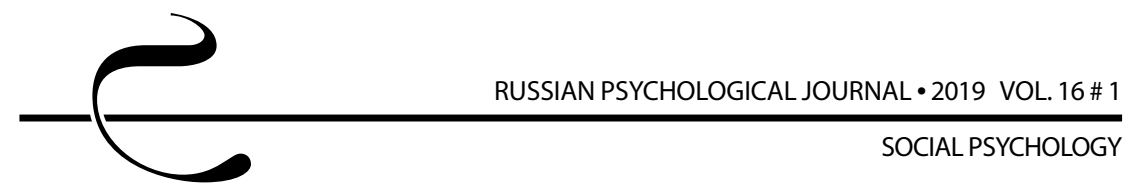

ниях // Человеческий фактор: проблемы психологии и эргономики. 2017. № 1 (81). C. 48-54.

12. Юношева М. А. Социальная активность молодежных общественных объединений в системе принятия социально значимых решений // В мире научных открытий. 2010. № 4-2. С. 46-48.

13. Попов Е. А., Максимова С. Г. Социальная активность населения и общественные гражданские инициативы // Политика и общество. 2012. № 7. C. 17-22.

14. Максимова С. Г. Гражданское сознание, гражданские инициативы и социальная активность населения как основы формирования гражданского общества в современной России // Вестник Пермского государственного гуманитарно-педагогического университета. Серия № 3. Гуманитарные и общественные науки. 2015. № 1. С. 116-131.

15. Акбарова А. А. Социальная активность как элемент социального самоопределения молодежи // Известия Саратовского университета. Новая серия. Акмеология образования. Психология развития. 2015. T. 4, № 1. C. 41-45.

16. Фомин А. А., Симанина А. И. Социальная активность, гражданская идентичность и личностная зрелость как проявления гражданского мировосприятия молодежи // Актуальные проблемы психологического знания. 2015. № 3. С. 123-135.

17. МустафинаД. Б. Формирование активной социальной позиции молодежи через волонтерскую деятельность как одного из видов социальной активности // Новая наука: Стратегии и векторы развития. 2015. № 6-2. C. 34-36.

18. Russo S., Amna E. When political talk translates into political action: The role of personality traits // Personality and individual differences. 2016. Vol. 100. P. 126-130. DOI: $10.1016 / j$.paid.2015.12.009

19. Reichert F., Print M. Mediated and moderated effects of political communication on civic participation // Information Communication \& Society. 2017. Vol. 20, Issue 8. P. 1162-1184. DOI: 10.1080/1369118X.2016.1218524

20. Roker D., Player K., \& Coleman J. Young People's Voluntary and Campaigning Activities as Sources of Political Education // Oxford Review of Education. 1999. Vol. 25, Issue 1-2. P. 185-198. DOI: $10.1080 / 030549899104206$

21. Gaby S. The Civic Engagement Gap(s): Youth Participation and Inequality From 1976 to 2009 //Youth \& Society. 2017. Vol. 49, Issue 7. P. 923-946. DOI: 10.1177/0044118X16678155

22. Исаева С. С., Никулина Е. Ю., Радченко Т. Е. Социальная активность молодежи как фактор развития современной России // Вестник Костромского государственного университета им. Н. А. Некрасова. Серия: Педагогика. 
Психология. Социальная работа. Ювенология. Социокинетика. 2012. T. 18, № 1-2. С. 212-213.

23. Родимушкина О. В., Черникова И. А., Яковлев О. В. Социальная напряженность и протестная активность в России // Общество и право. 2015. № 1 (51). С. 300-304.

24. Гайфуллин А. Ю., Рыбалко Н. В. Социальная активность молодежи: оценка и пути повышения // Вестник Башкирского университета. 2011. Т. 16, № 4. С. 1392-1396.

25. Kahne J. \& Bowyer B. The Political Significance of Social Media Activity and Social Networks // Political Communication. 2018. Vol. 35, Issue 3. P. 470-493. DOI: $10.1080 / 10584609.2018 .1426662$

26. Shiratuddin N., Hassan S., Mohd Sani M. A., Ahmad M. K., Aboo Talib Khalid K., Abdull Rahman N. L., Ahmad N. S. Y. Media and youth participation in social and political activities: Development of a survey instrument and its critical findings // Journal of Social Sciences and Humanities. 2017. Vol. 25. P. 1-19.

27. McFarland D. A., Thomas R. J. Bowling Young: How Youth Voluntary Associations Influence Adult Political Participation // American Sociological Review. 2006. Vol. 71. P. 401-425.

28. OosterhoffB., Ferris K. A., Metzger A. Adolescents' Sociopolitical Values in the Context of Organized Activity Involvement //Youth \& Society. 2017. Vol. 49, Issue 7. P. 947-967. DOI: 10.1177/0044118X14560528

29. Zani B. \& Barrett M. Engaged citizens? Political participation and social engagement among youth, women, minorities, and migrants // Human Affairs. 2012. Vol. 22, Issue 3. P. 273-282. DOI: 10.2478/s13374-012-0023-2

30. Yeshpanova D., Narbekova G., Biyekenova N., Kuchinskaya J., Mukanova O. Social Activity of Youth in Social and Cultural Measurement // Procedia Social and Behavioral Sciences. 2014. Vol. 140. P. 109-114. DOI: 10.1016/j. sbspro.2014.04.394

31. Завгородний М. Д. Социальная активность в сети интернет // Вестник Российского университета дружбы народов. Серия: Социология. 2012. № 2. С. 49-55.

32. Рябикина 3. И., Богомолова Е. И. Взаимосвязь личностных характеристик пользователей социальных сетей интернета с особенностями их активности в сети // Политематический сетевой электронный научный журнал Кубанского государственного аграрного университета. 2015. № 109. С. 1041-1057.

33. Пилишвили Т. С., Минаева А. Ю. Активность личности в социальных сетях и становление субъектности в информационном мире // Акмеология. 2016. № 1 (57). С. 84-88. 


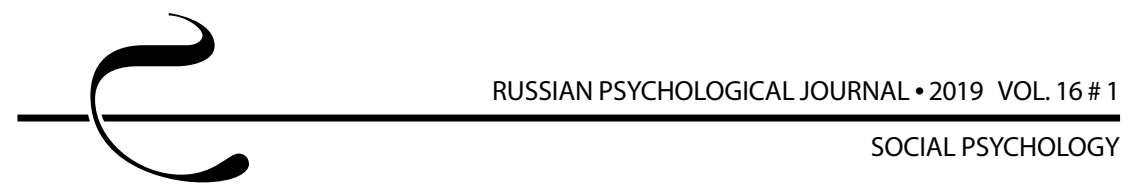

34. Зинчак Е. В., Сахаров А. С. Исследование зависимости между активностью соискателей в социальных сетях и их трудоустройством и карьерным ростом // Экономика и предпринимательство. 2014. № 12-3 (53-3). C. 457-463.

35. Белинская Е. П., Франтова Д. К. Активность в виртуальном взаимодействии как фактор конструирования идентичности пользователями социальных сетей: межпоколенные различия // Вестник РГГУ. Серия: Психология. Педагогика. Образование. 2017. № 3 (9). С. 28-43.

36. Митичева Т. И., Маслова В.С. Проблема активности молодежи в социальных сообществах интернет-сети // Альманах современной науки и образования. 2015. № 5 (95). С. 126-128.

37. Vitak J., Zube P., Smock A., Carr C. T., Ellison N., Lampe C. It's Complicated: Facebook Users' Political Participation in the 2008 Election // Cyberpsychology, Behavior and Social Networking. 2011. Vol. 14 (3). DOI: 10.1089/ cyber.2009.0226

38. Jost J. T., Barbera P., Bonneau R., Langer M., Metzger M., Nagler J., Sterling J., Tucker J. A. How Social Media Facilitates Political Protest: Information, Motivation, and Social Networks // Political Psychology. 2018. Vol. 39 (1). P. 85-118.

39. Ogan C., Varol O. What is gained and what is left to be done when content analysis is added to network analysis in the study of a social movement: Twitter use during Gezi Park // Information, Communication \& Society. 2017. Vol. 20, Issue 8. P. 1220-1238. DOI: 10.1080/1369118X.2016.1229006

40. Chan M., \& Guo J. The Role of Political Efficacy on the Relationship Between Facebook Use and Participatory Behaviors: A Comparative Study of Young American and Chinese Adults // Cyberpsychology, Behavior, and Social Networking. 2013. Vol. 16 (6). DOI: 10.1089/cyber.2012.0468

41. Купрейченко А. Б., Моисеев А. С. Социальное самоопределение российского городского среднего класса // Ученые записки ИМЭИ. 2011. № 2 (2). C. 71-84.

42. Лабунская В. А., Наровская Я. Б. Типы преобразования внешнего облика как отражение направленности преобразовательной активности субъекта в социальном общении // Мир психологии. 2006. № 4. С. 96-104.

43. Толстенёва У. Л. Экзистенциальный опыт и социальная активность личности // Психология и психотехника. 2016. № 7. С. 614-621.

44. Щемелева И. И. Социальные технологии управления социальной активностью студенческой молодежи // Вопросы управления. 2016. № 4 (22). С. 86-92.

45. Шамионов Р. М. Социализация личности: системно-диахронический подход // Психологические исследования: электронный научный журнал. 2013. Т. 6, № 27. С. 8. 
46. Ананьев Б. Г. Человек как предмет познания. СПб.: Питер, 2001. 288 с.

47. Ломов Б. Ф. Системность в психологии: Избранные психологические труды. М.: Изд-во Московского психолого-социального института, 2003. 424 C.

48. Месарович М., Мако Д., Такахара И. Теория иерархических многоуровневых систем. М.: Мир, 1973. 344 с.

49. Карпов А. В. Психология деятельности: В 5 т. Т. 1: Метасистемный подход. М.: Изд-во РАО, 2015. 546 с.

50. Рябикина 3. И. Субъектно-бытийный подход к личности и ее со-бытию со значимыми другими // Психология субъекта и психология человеческого бытия / под ред. В. В. Знакова, 3. И. Рябикиной, Е. А. Сергиенко. Краснодар: Изд-во Кубанского гос. ун-та, 2010. С. 130-157.

51. Сергиенко E. A. Реализация принципа развития в исследованиях психологии субъекта // Психологический журнал. 2017. Т. 38, № 2. С. 5-18.

52. Знаков $B$. В. Теоретические основания психологии человеческого бытия // Психологический журнал. 2013. Т. 34, № 2. С. 29-38.

53. Знаков $B$. В. Понимание субъектом трех реальностей человеческого бытия // Известия Саратовского университета. Новая серия. Акмеология образования. Психология развития. 2014. Т. 3, № 4. С. 311-316.

54. Анцыферова Л.И. Методологические проблемы психологии развития // Принцип развития в психологии. М.: Наука, 1978. С. 3-20.

55. Асеев В. Г. О диалектике детерминации психического развития // Принцип развития в психологии. М.: Наука, 1978. С. 21-34.

56. Шамионов Р. М. Принцип диахронии в исследовании социализации личности // Известия Саратовского университета. Новая серия. Серия: Философия. Психология. Педагогика. 2013. Т. 13, № 1. С. 79-84.

57. Григорьева М. В. Диахронический подход к исследованию процессов социально-психологической адаптации личности // Известия Саратовского университета. Новая серия. Серия: Философия. Психология. Педагогика. 2013. Т. 13, № 1. С. 54-58.

58. Крюков В. В. Диахронический анализ реальности // Идеи и идеалы. 2011. T. 1, № 2. С. 23-43.

59. Сергиенко Е. А. Принципы психологии развития: современный взгляд // Психологические исследования. 2012. T. 5, № 24. C. 1. URL: http://psystudy. ru (дата обращения: 05.04.2018).

60. Прыгин Г. С. Психология самостоятельности. Ижевск, Наб. Челны: Изд-во Института управления, 2009. 304 с.

61. Rotter J. B. Some comments on the "Cognates of personal control" // Applied \& Preventive Psychology. 1992. № 1. P. 127-129. DOI: $10.1016 /$ S09621849(05)80154-4 
62. Ушаков Д. В. Социальный интеллект как вид интеллекта // Социальный интеллект: Теория, измерение, исследования / под ред. Д.В.Люсина, Д. В. Ушакова. М.: Изд-во ИП РАН, 2004. С. 11-28.

\section{References}

1. Mikhailovskii N. K. Heroes and crowd. In: Izbr. trudy po sotsiologii [Collected works on sociology]. St. Petersburg, Alethea Publ., V. 2, 1998. 406 p.

2. McDougall W. Osnovnye problemy sotsial'noi psikhologii [The main problems of social psychology]. Moscow, Kosmos Publ., 2016. 282 p.

3. Grigor'eva M. V. Synergy of school interactions. Izvestiya Saratovskogo universiteta. Novaya seriya. Seriya: Filosofiya. Psikhologiya. Pedagogika Izvestiya of Saratov University. New series. Series: Philosophy. Psychology. Pedagogy, 2009, V. 9, no. 2, pp. 68-73 (in Russian).

4. Shamionov R. M. Psychological characteristics of personal social activity. Mir psikhologii - World of Psychology, 2012, no. 3, pp. 145-154 (in Russian).

5. Shamionov R. M., Grigor'eva M. V. Psikhologiya sotsial'noi aktivnosti molodezhi: problemy i riski [Psychology of social activity of youth: Problems and risks]. Saratov, Saratov University Publ., 2012. 384 p.

6. Abul'khanova-Slavskaya K. A. Psikhologiya i soznanie lichnosti (problemy metodologii, teorii i issledovaniya real'noi lichnosti) [Psychology and consciousness of personality: Problems of methodology, theory, and research of real personality]. Moscow, Moscow Psychological and Social Institute Publ.; Voronezh, Modek Publ., 1999. 224 p.

7. Sokolova E. S. Structural approach to understanding the motivation for social activity of young people. Knowledge. Understanding. Skill, 2008, no. 2. Available at:http://www.zpu-journal.ru/e-zpu/2008/2/Sokolova/ (Accessed 08 April 2018).

8. Eremina L. I. Correlation of creativity and social activity of students in the socio-reformative activity. Izvestiya Saratovskogo universiteta. Novaya seriya. Akmeologiya obrazovaniya. Psikhologiya razvitiya - Izvestiya of Saratov University. New Series: Educational Acmeology. Developmental Psychology, 2015, V. 4, no. 2, pp. 155-159 (in Russian).

9. Grigor'ev A. V. Personal traits and characteristics of attitudes towards activity as predictors of personal socio-psychological adaptation depending on the directions of the realized activity. Modern Problems of Science and Education, 2014, no. 5. p. 630. Available at: https://www.science-education.ru/ru/article/ view?id=14546 (Accessed 08 April 2018).

10. Zabolotskii V. A. Mechanisms of motivation affecting students' social activity. Kazanskaya nauka - Kazan Science, 2015, no. 6, pp. 202-204 (in Russian).

11. Balabanova E. S. Development of ideas on social activity among young people in Russian socio-psychological research. Chelovecheskii faktor: 
problemy psikhologii i ergonomiki - Human Factors: Problems of Psychology and Ergonomics, 2017, no. 1 (81), pp. 48-54 (in Russian).

12. Yunosheva M. A. Social activity of youth public associations in the system making socially significant decisions. V mire nauchnykh otkrytii-In the World of Scientific Discoveries, 2010, no. 4-2, pp. 46-48 (in Russian).

13. Popov E. A., Maksimova S. G. Social activity of population and public civil initiatives. Politika iobshchestvo - Politics and Society, 2012, no. 7, pp. 17-22 (in Russian).

14. Maksimova S. G. Civic consciousness, civic initiatives, and social participation as a basis for the formation of civil society in modern Russia. Vestnik Permskogo gosudarstvennogo gumanitarno-pedagogicheskogo universiteta. Seriya № 3. Gumanitarnye i obshchestvennye nauki - Bulletin of Perm State University of Pedagogical Sciences and Humanities. Series 3: Humanities and Social Sciences, 2015, no. 1, pp. 116-131 (in Russian).

15. Akbarova A. A. Social activity as an element of social self-determination of youth. Izvestiya Saratovskogo universiteta. Novaya seriya. Akmeologiya obrazovaniya. Psikhologiya razvitiya - Izvestiya of Saratov University. New Series: Educational Acmeology. Developmental Psychology, 2015, V. 4, no. 1, pp. 41-45 (in Russian).

16. Fomin A. A., Simanina A. I. Social engagement, civic identity and personal maturity as a manifestation of civic attitude of youth. Aktual'nye problemy psikhologicheskogo znaniya - Actual Problems of Psychological Knowledge, 2015, no. 3, pp. 123-135 (in Russian).

17. Mustafina D. B. Formation of active social position of youth through volunteer activity as a type of social activity. Novaya nauka: Strategii i vektory razvitiya - New Science: Strategies and Vectors of Development, 2015, no. 6-2, pp. 34-36 (in Russian).

18. Russo S., Amna E. When political talk translates into political action: The role of personality traits. Personality and Individual Differences, 2016, V. 100, pp. 126-130. DOI: 10.1016/j.paid.2015.12.009

19. Reichert F., Print M. Mediated and moderated effects of political communication on civic participation. Information Communication \& Society, 2017, V. 20, Issue 8, pp. 1162-1184. DOI: 10.1080/1369118X.2016.1218524

20. Roker D., Player K., \& Coleman J. Young people's voluntary and campaigning activities as sources of political education. Oxford Review of Education, 1999, V. 25, Issue 1-2, pp. 185-198. DOI: 10.1080/030549899104206

21. Gaby S. The civic engagement gap(s): Youth participation and inequality from 1976 to 2009. Youth \& Society, 2017, V. 49, Issue 7, pp. 923-946. DOI: $10.1177 / 0044118 \times 16678155$

22. Isaeva S. S., Nikulina E. Yu., RadchenkoT. E. Social activity of youth as a factor of the development of modern Russia. Vestnik Kostromskogo gosudarstvennogo 
universiteta im. N. A. Nekrasova. Seriya: Pedagogika. Psikhologiya. Sotsial'naya rabota. Yuvenologiya. Sotsiokinetika - Vestnik Kostroma state university. Series: Pedagogy. Psychology. Juvenology. Sociokinetics, 2012, V. 18, no. 1-2, pp. 212-213 (in Russian).

23. Rodimushkina O. V., Chernikova I. A., Yakovlev O. V. Social tensions and protest potential in the Russian Federation. Obshchestvo i parvo - Society and Law, 2015, no. 1 (51), pp. 300-304 (in Russian).

24. Gaifullin A. Yu., Rybalko N.V. Social activity of youth: the evaluation and ways to improve. Vestnik Bashkirskogo universiteta - Bulletin of Bashkir University, 2011, V. 16, no. 4, pp. 1392-1396 (in Russian).

25. Kahne J. \& Bowyer B. The political significance of social media activity and social networks. Political Communication, 2018, V. 35, Issue 3, pp. 470-493. DOI: $10.1080 / 10584609.2018 .1426662$

26. Shiratuddin N., Hassan S., Mohd Sani M. A., Ahmad M. K., Aboo Talib Khalid K., Abdull Rahman N. L., Ahmad N. S. Y. Media and youth participation in social and political activities: Development of a survey instrument and its critical findings. Journal of Social Sciences and Humanities, 2017, V. 25, pp. 1-19.

27. McFarland D. A., Thomas R. J. Bowling young: How youth voluntary associations influence adult political participation. American Sociological Review, 2006, V. 71, pp. 401-425.

28. Oosterhoff B., Ferris K. A., Metzger A. Adolescents' sociopolitical values in the context of organized activity involvement. Youth \& Society, 2017, V. 49, Issue 7, pp. 947-967. DOI: 10.1177/0044118X14560528

29. Zani B. \& Barrett M. Engaged citizens? Political participation and social engagement among youth, women, minorities, and migrants. Human Affairs, 2012, V. 22, Issue 3, pp. 273-282. DOI: 10.2478/s13374-012-0023-2

30. Yeshpanova D., Narbekova G., Biyekenova N., Kuchinskaya J., Mukanova O. Social activity of youth in social and cultural measurement. ProcediaSocial and Behavioral Sciences, 2014, V. 140, pp. 109-114. DOI: 10.1016/j. sbspro.2014.04.394

31. Zavgorodnii M. D. Social activity on the Internet. Vestnik Rossiiskogo universiteta druzhby narodov. Seriya: Sotsiologiya - Bulletin of Peoples' Friendship University of Russia. Series: Sociology, 2012, no. 2, pp. 49-55 (in Russian).

32. Ryabikina Z. I., Bogomolova E. I. Interrelations between personal characteristics of users of the Internet social networks and features of their activity in a network. Polythematic Online Scientific Journal of Kuban State Agrarian University, 2015, no. 109, pp. 1041-1057.

33. Pilishvili T. S., Minaeva A. Yu. Social networking activity of personality and subjectivity formation in the information world. Akmeologiya-Acmeology, 2016, no. 1 (57), pp. 84-88 (in Russian). 
34. Zinchak E. V., Sakharov A. S. Studying the relationship between the activity of applicants in social networks and their employment and career growth. Ekonomika i predprinimatel'stvo - Economics and Entrepreneurship, 2014, no. 12-3 (53-3), pp. 457-463 (in Russian).

35. Belinskaya E. P., Frantova D. K. Activity in the virtual interaction as a factor of identity construction by social networks users: intergenerational differences. Vestnik RGGU. Seriya: Psikhologiya. Pedagogika. Obrazovanie - Bulletin of Russian State University for the Humanities. Series: Psychology. Pedagogy, 2017, no. 3 (9), pp. 28-43 (in Russian).

36. Miticheva T. I., Maslova V. S. Problem of youth's activity in social communities of internet network. Al'manakh sovremennoi nauki i obrazovaniya-Almanac of Modern Science and Education, 2015, no. 5 (95), pp. 126-128 (in Russian).

37. Vitak J., Zube P., Smock A., Carr C. T., Ellison N., Lampe C. It's complicated: Facebook users' political participation in the 2008 Election. Cyberpsychology, Behavior and Social Networking, 2011, V. 14 (3). DOI: $10.1089 /$ cyber.2009.0226

38. Jost J. T., Barbera P., Bonneau R., Langer M., Metzger M., Nagler J., Sterling J., Tucker J. A. How social media facilitates political protest: information, motivation, and social networks. Political Psychology, 2018, V. 39 (1), pp. 85-118.

39. Ogan C., Varol O. What is gained and what is left to be done when content analysis is added to network analysis in the study of a social movement: Twitter use during Gezi Park. Information, Communication \& Society, 2017, V. 20, Issue 8, pp. 1220-1238. DOI: 10.1080/1369118X.2016.1229006

40. Chan M., \& Guo J. The role of political efficacy on the relationship between Facebook use and participatory behaviors: A comparative study of young American and Chinese adults. Cyberpsychology, Behavior, and Social Networking, 2013, V. 16 (6). DOI: 10.1089/cyber.2012.0468

41. Kupreichenko A. B., Moiseev A. S. Social self-determination of the Russian urban middle class. Uchenye zapiski IMEI - Proceedings of the Institute of the World Economy and Informatization, 2011, no. 2 (2), pp. 71-84 (in Russian).

42. Labunskaya V. A., Narovskaya Ya. B. Types of transformation of the appearance as a reflection of the focus of transforming activity of a subject in social communication. Mir psikhologii - The World of Psychology, 2006, no. 4, pp. 96-104 (in Russian).

43. Tolsteneva U. L. Existential experience and social activity of personality. Psikhologiya i psikhotekhnika - Psychology and Psychotechnics, 2016, no. 7, pp. 614-621 (in Russian).

44. Shchemeleva I. I. Social technologies for managing students' social activity. Voprosy upravleniya - Management Issues, 2016, no. 4 (22), pp. 86-92 (in Russian). 
45. Shamionov R. M. Socialization of personality: A systematic diachronic approach. Psikhologicheskie issledovaniya, 2013, V. 6, no. 27, p. 8 (in Russian).

46. Anan'ev B. G. Chelovek kak predmet poznaniya [Man as a subject of knowledge]. St. Petersburg, Piter Publ., 2001. 288 p.

47. Lomov B. F. Sistemnost'v psikhologii: Izbrannye psikhologicheskie trudy [Consistency in psychology: Selected psychological works]. Moscow, Moscow Institute of Psychology and Sociology Publ., 2003. 424 p.

48. Mesarovic M., Macko D., Takahara I. Teoriya ierarkhicheskikh mnogourovnevykh sistem [Theory of hierarchical, multilevel, systems]. Moscow, Mir Publ., 1973. 344 p.

49. Karpov A. V. Metasystem approach. In: Psikhologiya deyatel'nosti [Psychology of activity: in 5 volumes]. Moscow, RAE Publ., 2015, V. 1.546 p.

50. Ryabikina Z. I. The subjective-existential approach to the person and the analysis of his/her co-existence with others. In: V. V. Znakov, Z. I. Ryabikina, E. A. Sergienko (eds.) Psikhologiya sub"ekta i psikhologiya chelovecheskogo bytiya [Human psychology and psychology of human existence]. Krasnodar, Kuban State University Publ., 2010, pp. 130-157.

51. Sergienko E. A. Implementation of the principle of development in human psychology studies. Psikhologicheskii zhurnal, 2017, V. 38, no. 2, pp. 5-18 (in Russian).

52. Znakov V.V. Theoretical foundations of the psychology of human existence. Psikhologicheskii zhurnal, 2013, V. 34, no. 2, pp. 29-38 (in Russian).

53.Znakov V. V. Subjective understanding of three realities of human existence. Izvestiya of Saratov University. New series: Educational Acmeology. Developmental Psychology, 2014, V. 3, no. 4, pp. 311-316 (in Russian).

54. Antsyferova L. I. Methodological problems of developmental psychology. Printsip razvitiya v psikhologii - The Principle of Development in Psychology. Moscow, Nauka Publ., 1978, pp. 3-20 (in Russian).

55. Aseev V. G. On the dual structure determination of mental processes. Printsip razvitiya v psikhologii - The Principle of Development in Psychology. Moscow, Nauka Publ., 1978, pp. 21-34 (in Russian).

56. Shamionov R. M. Principle of diachrony in the study of socialization of personality. Izvestiya Saratovskogo universiteta. Novaya seriya. Seriya: Filosofiya. Psikhologiya. Pedagogika - Izvestiya of Saratov University. New series: Philosophy. Psychology. Pedagogy, 2013, V. 13, no. 1, pp. $79-84$ (in Russian).

57. Grigor'eva M.V. Diachronic approach to the study of the processes of sociopsychological adaptation of personality. Izvestiya Saratovskogo universiteta. Novaya seriya. Seriya: Filosofiya. Psikhologiya. Pedagogika - Izvestiya of Saratov University. New series: Philosophy. Psychology. Pedagogy, 2013, V. 13, no. 1, pp. 54-58 (in Russian). 
58. Kryukov V. V. Diachronic analysis of reality. Idei $i$ idealy - Ideas and Ideals, 2011 , V. 1, no. 2, pp. 23-43.

59. Sergienko E. A. Principles of developmental psychology: A modern view. Psikhologicheskie issledovaniya, 2012, V. 5, no. 24, p. 1. Available at: http:// psystudy.ru (Accessed 05 April 2018).

60. Prygin G. S. Psikhologiya samostoyatel'nosti [Psychology of independence]. Izhevsk, Naberezhnye Chelny, Institute of Management Publ., 2009. 304 p.

61. Rotter J. B. Some comments on the "Cognates of personal control". Applied \& Preventive Psychology, 1992, no. 1, pp. 127-129. DOI: $10.1016 /$ S09621849(05)80154-4

62. Ushakov D. V. Social intelligence as a type of intelligence. In: D. V. Lyusin, D. V. Ushakov (eds.) Sotsial'nyi intellekt: Teoriya, izmerenie, issledovaniya [Social intelligence: Theory, measurement, and research]. Moscow, Institute of Psychology RAS Publ., 2004, pp. 11-28. 